\title{
USO TERAPÊUTICO DOS CANABINOIDES ENCONTRADOS NA CANNABIS SATIVA
}

\section{ARTIGO DE REVISÃO}

SILVA, Renan Cicero Coelho ${ }^{1}$

SILVA, Renan Cicero Coelho. Uso Terapêutico dos Canabinóides encontrados na Cannabis sativa. Revista Científica Multidisciplinar Núcleo do Conhecimento. Ano 04, Ed. 07, Vol. 01, pp. 106-120. Julho de 2019. ISSN: 2448-0959

\section{RESUMO}

Vários canabinoides presentes na Cannabis sativa apresentam propriedades terapêuticas importantes. Suas primeiras utilizaçãoes terapêuticas ocorreram há mais de 2000 anos atrás. Serão abordados dois dos principais canabinoides encontrados na Cannabis sativa, o Tetra-hidrocanabinol, também conhecido como THC e o Canabidiol, conhecido como CBD, seus mecanismos de ação e uso terapêutico. Atualmente, descobertas importantes sobre os canabinoides extraídos da planta Cannabis sativa contribuíram para entender o funcionamento dos receptores CB1 e $\mathrm{CB} 2$, que são receptores acoplados à proteína $\mathrm{G}$ dentro do sistema nervoso central, assim como de endocanabinoides, como a Anandamida e 2-arachidonoyl glicerídeos (2-AG). Medicamentos a base de canabinoides extraídos da Cannabis sativa tem apresentado resultados excelentes no tratamento de várias doenças, onde o tratamento convencional teve pouco ou nenhum sucesso. Qual a situação atual da pesquisa e o uso destes medicamentos no mundo e especialmente no Brasil, que tem potencial para se tornar referência mundial neste tipo de pesquisa e desenvolvimento de novos medicamentos.

\footnotetext{
${ }^{1}$ Especialista em Farmacologia e Interações Medicamentosas - Centro Universitário Internacional (UNINTER), Farmacêutico - Universidade Presidente Antônio Carlos (UNIPAC).
} 


\section{MULTIDISCIPLINARY SCIENTIFIC JOURNAL REVISTA CIENTÍFICA MULTIDISCIPLINAR NÚCLEO DO

Palavras Chave: Cannabis sativa, canabinoides, Tetra-hidrocanabinol, Canabidiol.

\section{INTRODUÇÃO}

A Cannabis sativa (Figura1) é uma planta herbácea da família das Canabiáceas (Cannabaceae), que apresenta grande potencial terapêutico. Nativa do centro e do sul da Ásia hoje é amplamente cultivada em muitas partes do mundo, principalmente nas regiões de clima tropical.

Figura 1:Cannabis sativa ${ }^{16}$

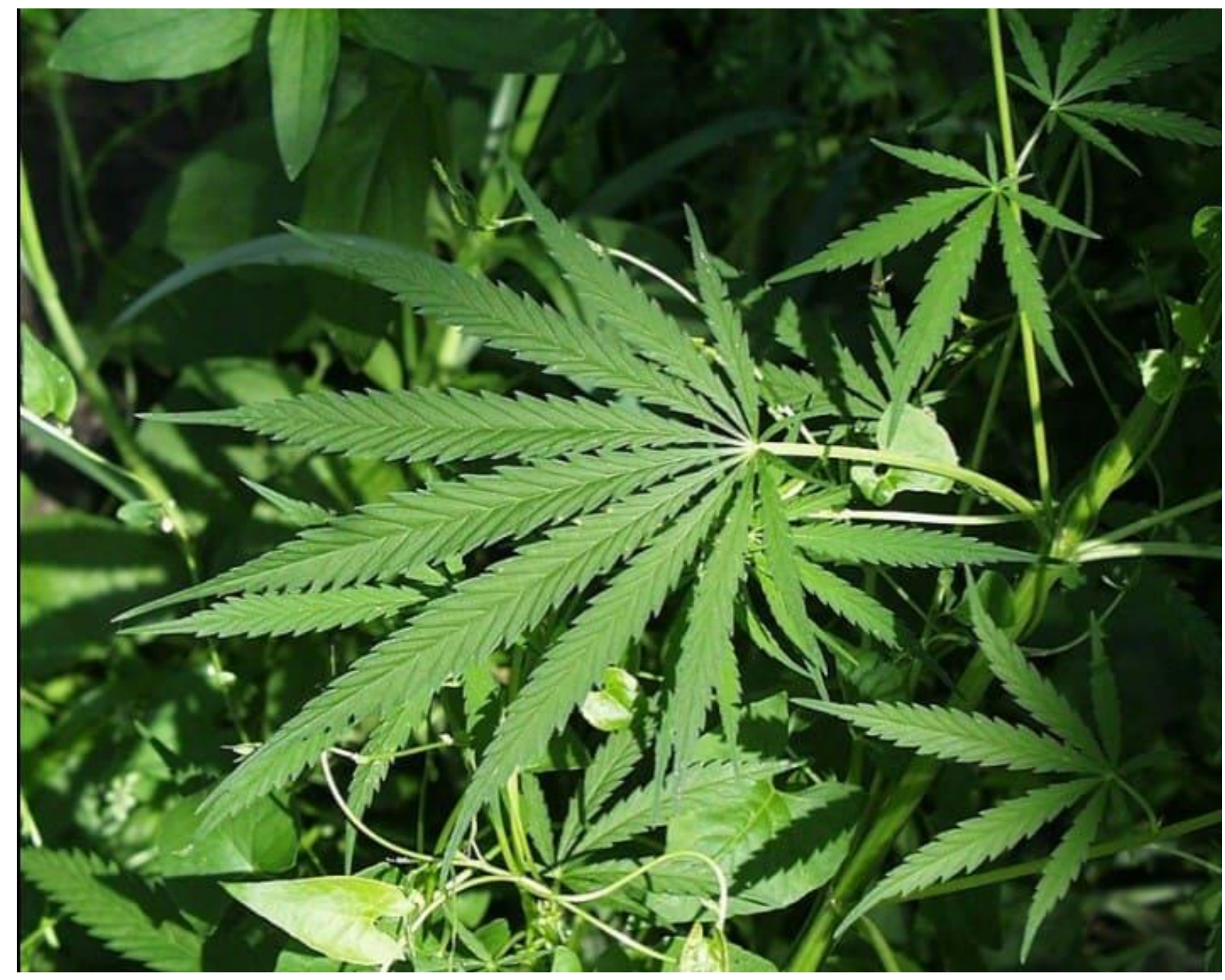

Os primeiros registros históricos do uso da Cannabis sativa são na fabricação de papel que datam de 8000 anos a.C. na China. 
Sua evidência cultural mais antiga,vem da mais antiga cultura neolítica conhecida na China, o Yangshao, que apareceu ao longo do vale do rio Amarelo. De 5.000 a 3.000 $\mathrm{aC}$, a economia do Yangshao foi conduzida pela Cannabis, evidências arqueológicas mostram que eles usavam roupas, tecidos e cera a base de Cannabis sativa.

O uso de cannabis no antigo Egito foi registrado antes de $2.000 \mathrm{aC}$, encontrado em rolos que descrevem plantas medicinais. Foi documentado pela primeira vez em Kemet (antigo Egito) para tratar olhos doloridos e cataratas. De acordo com Diodorus Siculus, historiador grego siciliano (século 1 antes de Cristo), as mulheres egípcias usavam cannabis como medicação para aliviar a tristeza e o mau humor. Em 1.213 aC. O pólen de cannabis foi encontrado na múmia de Rameses II. Pesquisas adicionais ligaram o pólen de cannabis a todas as múmias reais conhecidas.

Seshat, era a antiga deusa egípcia da sabedoria, do conhecimento e da escrita. Ela foi vista como um guardião de escrutinios e gravadores, e seu nome significa que ela scrivens, ou seja, ela que é o escriba, e é creditada por inventar a escrita. Ela também se tornou identificada como a deusa da contabilidade, arquitetura, astronomia, astrologia, construção, matemática e topografia. A Mistress of the House of Books é outro título para Seshat, sendo a divindade cujos sacerdotes supervisionaram a biblioteca na qual os manuscritos dos conhecimentos mais importantes foram reunidos e os feitiços foram preservados. Na figura 2, Seshat é retratada em uma pele de leopardo, inscrevendo os anos de reinado para o rei na costela das folhas de palmeira que servia para contar os anos e, assim, se tornou o hieróglifo para o ano. Acima de sua cabeça há uma folha de Cannabis sativa, que parece representar seu elevado estado de consciência. 
Figura 2: Seshat, antiga deusa do Egito ${ }^{29}$

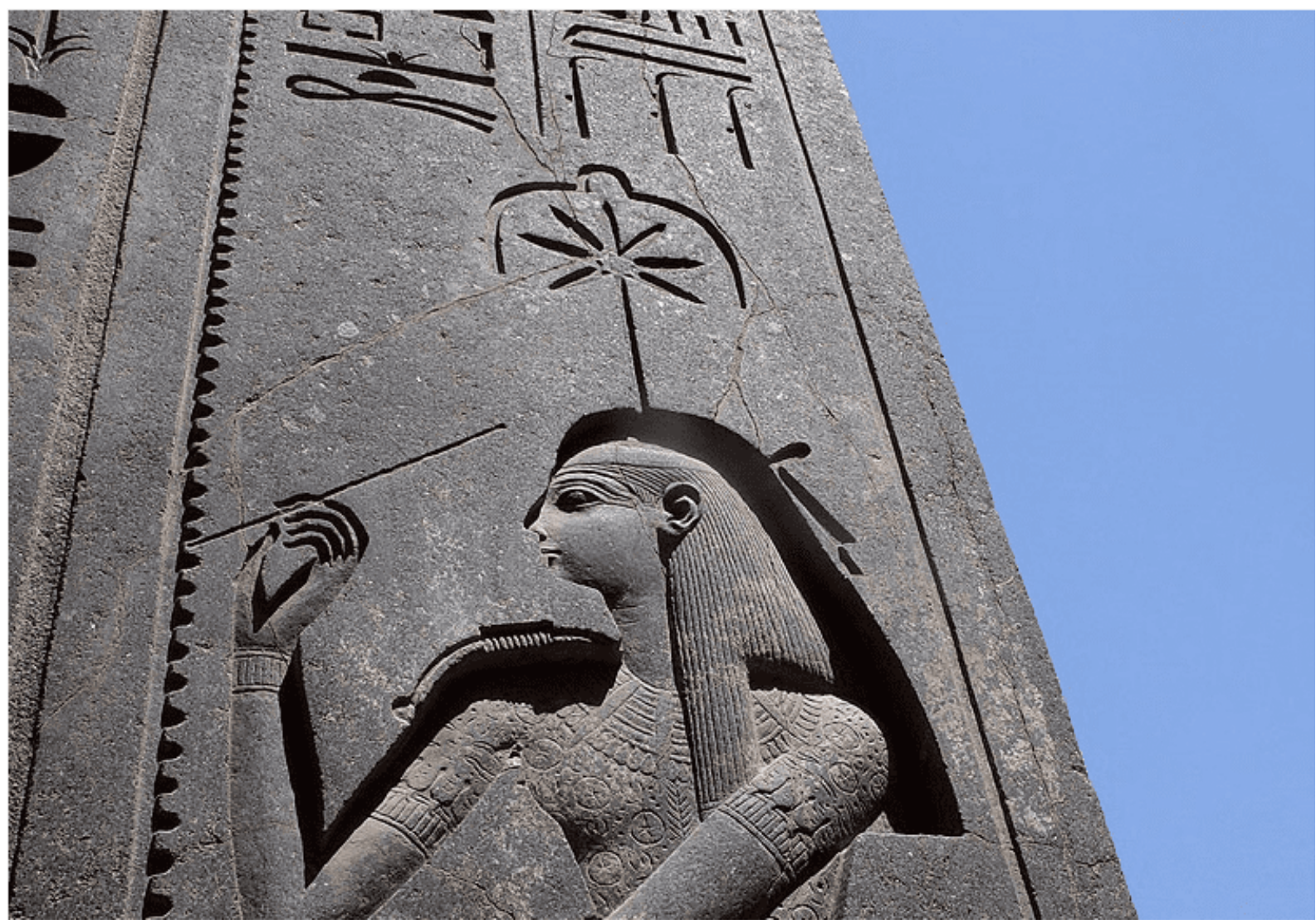

Os chineses descreveram os potenciais terapêuticos desta planta no Pen-Ts'aoChing, considerada a primeira farmacopéia conhecida do mundo, há 2.000 anos atrás, e os assírios, cerca de 300 anos atrás, consideravam a Cannabis como o principal medicamento de sua farmacopéia e de acordo com sua utilização recebia um nome: qunnabu, quando era utilizada em rituais religiosos; azallu, um termo medicinal assim como hemp; gan-zi-gunnu, o qual significava a droga que extrai a mente. $O$ uso medicinal da Cannabis era proibido em boa parte do mundo, incluindo o Brasil, mas devido a alguns estudos e relatos feitos por pacientes, que dizem ter grande melhoria na qualidade de vida, especialmente os que fazem tratamento contra o câncer, esclerose múltipla, AIDS, epilepsia o e síndrome de Tourette, síndrome que causa movimentos involuntários, hoje o uso para fins medicinais é permitido em alguns estados americanos e em países como Holanda, Bélgica e também no Brasil. 


\section{EFEITOS TERAPÊUTICOS}

Os efeitos terapêuticos relacionados a Cannabis sativa devem-se a alta concentração de compostos psicoativos, altamente lipossolúveis,que atravessam a barreira hematoencefálica alcançando o sistema nervoso central. Estes compostos são principalmente os canabinóides, uma classe de compostos químicos produzidos pela Cannabis que agem nos receptores CB1 e CB2 do sistema canabinóide endógeno. O sistema endocanabinóide compreende os receptores, os agonistas endógenos e o aparato bioquímico relacionado, responsável por sintetizar essas substâncias e realizar determinadas ações, como a liberação de neurotransmissores no cérebro em vários processos neurobiológicos. Os receptores foram nomeados pela União Internacional de Farmacologia Básica e Clínica (International Union of Basic and Clinical Pharmacology - IUPHAR), de acordo com sua ordem de descoberta, como receptores CB1 e CB2. Ambos são receptores acoplados à proteína $G$. Dentro do sistema nervoso central, o CB1 está primariamente localizado nos terminais nervosos pré-sinápticos e é responsável pela maioria dos efeitos neurocomportamentais dos canabinoides. O CB2, ao contrário, é o principal receptor de canabinoide no sistema imune, mas também pode expressar-se nos neurônios.

A concentração de canabinoides pode variar de acordo com fatores genéticos, ambientais e principalmente tempo de cultivo e tratamento da amostra, processo que envolve desde a maturação da planta até secagem, armazenamento e extração.

Na tabela 1 observamos algumas das principais substâncias químicas que já foram encontradas na Cannabis sativa. 
Tabela 1: Substâncias químicas encontradas na Cannabis sativa ${ }^{11}$

\begin{tabular}{|c|c|c|c|}
\hline Classe & $\begin{array}{l}\text { Número de compostos } \\
\text { encontrados na planta }\end{array}$ & Classe & $\begin{array}{l}\text { Número de compostos } \\
\text { encontrados na planta }\end{array}$ \\
\hline Canabinóides & 61 & Cetonas simples & 13 \\
\hline Canabigerol (CBG) & 6 & Ácidos simples & 20 \\
\hline Canabicromeno (CBC) & 4 & Ácidos graxos & 12 \\
\hline Canabidiol (CBD) & 7 & Esteres e lactonas simples & 13 \\
\hline$\Delta^{10 n}-\mathrm{THC}$ & 9 & Esteróides & 11 \\
\hline$\Delta^{200}-\mathrm{THC}$ & 2 & Açúcares e análogos & 34 \\
\hline Canabiciclol (CBL) & 3 & Monossacarideos & 13 \\
\hline Canabielsoin (CBE) & 3 & Dissacarideos & 2 \\
\hline Canabinol (CBN) & 6 & Polissacarídeos & 5 \\
\hline Canabinodiol (CBND) & 2 & Ciclitóis & 12 \\
\hline Canabitriol (CBT) & 6 & Amino-açúcares & 2 \\
\hline Outros canabinóides & 13 & Terpenos & 103 \\
\hline Compostos Nitrogenados & 20 & Monoterpenos & 58 \\
\hline Bases quartenárias & 5 & Sesquiterpenos & 38 \\
\hline Amidas & 1 & Diterpenos & 1 \\
\hline Aminas & 12 & Triterpenos & 2 \\
\hline Alcalóides espermidinas & 2 & Mistura de terpenóide & 4 \\
\hline Aminoácidos & 18 & Fenóis nao-canabinóides & 16 \\
\hline Proteinas, glicoproteinas e enzimas & 9 & Glicosídeos Flavonóide & 19 \\
\hline Hidrocarbonetos & 50 & Vitaminas & 1 \\
\hline Álcoois simples & 7 & Pigmentos & 2 \\
\hline Aldeidos simples & 12 & Total & 421 \\
\hline
\end{tabular}

$\mathrm{Na}$ figura 3 estão destacados os principais canabinóides naturais já classificados. Todos derivam de compostos do tipo cannabigerol e diferem principalmente na forma como este precursor é ciclizado, em destaque também estão alguns dos principais efeitos terapêuticos já identificados. 
Figura 3: Principais canabinóides naturais já classificados ${ }^{28}$

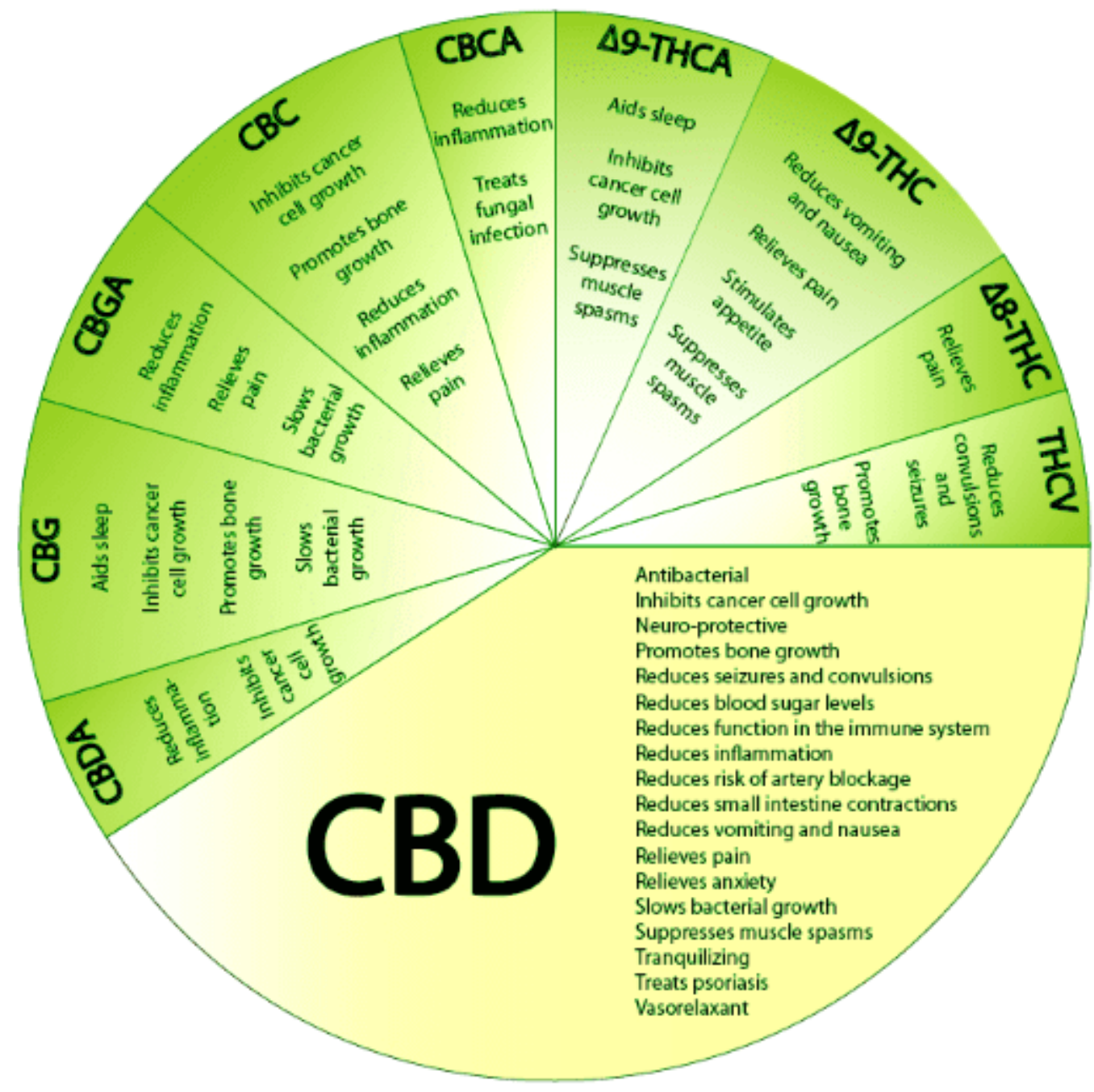

\section{MECANISMO DE AÇÃO}

Os mecanismos para que ocorram os efeitos terapêuticos no sistema canabinóide endógeno são agonismo ou o antagonismo nos receptores CB1 e CB2. Substâncias agonistas agem estimulando ou provocando ação nos receptores, já as substâncias antagonistas agem como bloqueadores dos receptores, diminuindo, modificando ou anulando as respostas a substância agonista presente nos neurotransmissores do organismo. 
O Tetra-hidrocanabinol,

também

conhecido

como

THC

(do inglês Tetrahydrocanabinol), $\Delta^{9}$-THC, $\Delta^{9}$-tetra-hidrocanabinol (delta-9-tetrahidrocanabinol) é a principal substância psicoativa encontrada na Cannabis sativa.

Figura 4: Fórmula estrutural do Tetra-hidrocanabinol

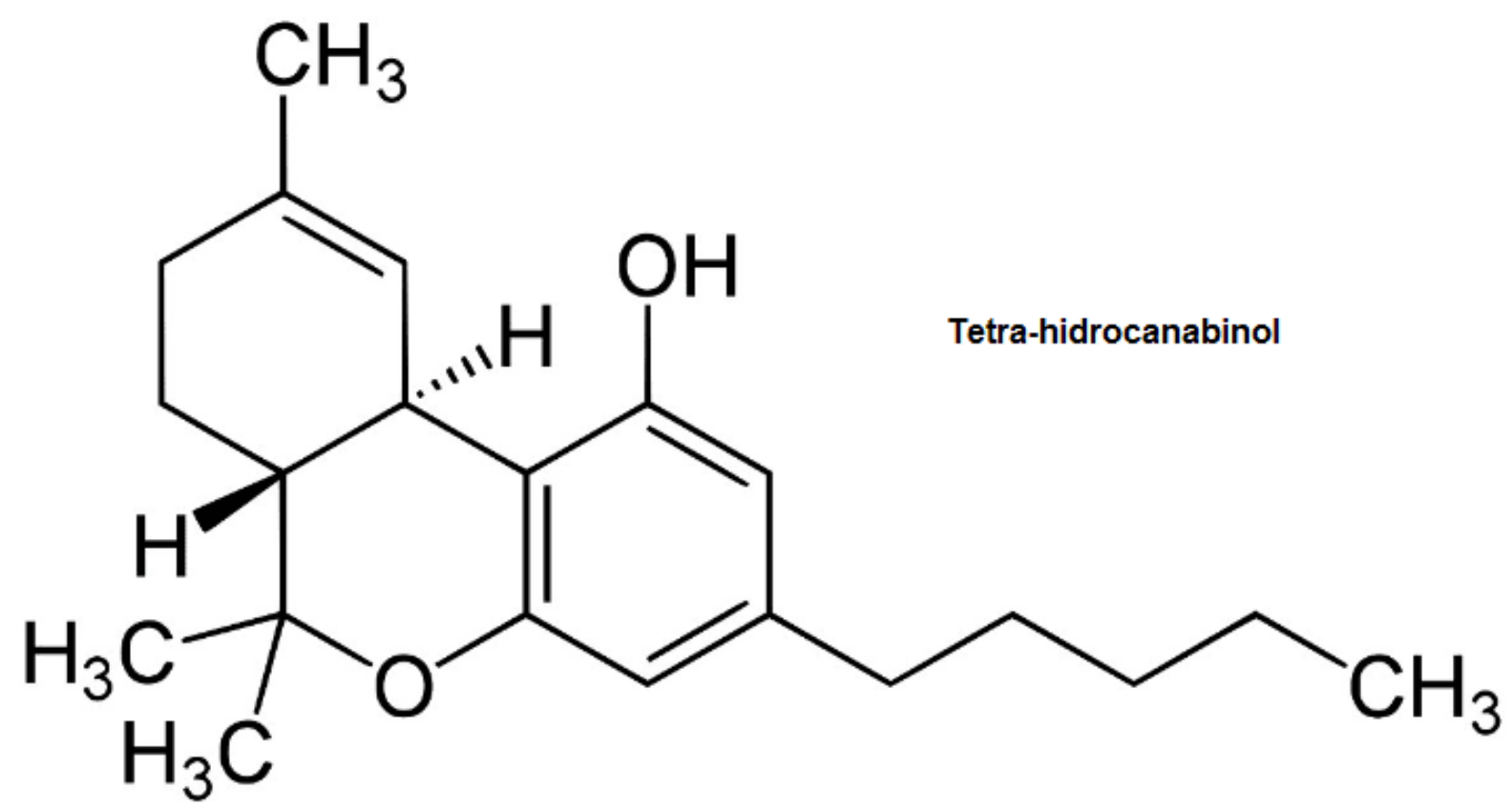

O primeiro caso comprovado de isolamento, em forma pura do THC, foi reportado, em 1964, por Gaoni e Mechoulam.

Composto da família dos fenóis é encontrado em todas as partes da planta, mas

O THC é um agonista e excitatório, ou seja, um canabinóide agonista que mimetiza a ação de substâncias agonistas endógenas ao corpo, presentes no sistema endocanabinoide. Ele se liga e ativa receptores CB1, ao ativar esses receptores, o THC interfere no seu funcionamento normal.

Os efeitos psicoativos do THC são principalmente mediados pela ativação de receptores de canabinóides, o que resulta em uma diminuição da concentração da molécula de segundo comparador de AMPc através da inibição da adenilato ciclase. 
Figura 5: Mecanismo de ação do THC ${ }^{30}$

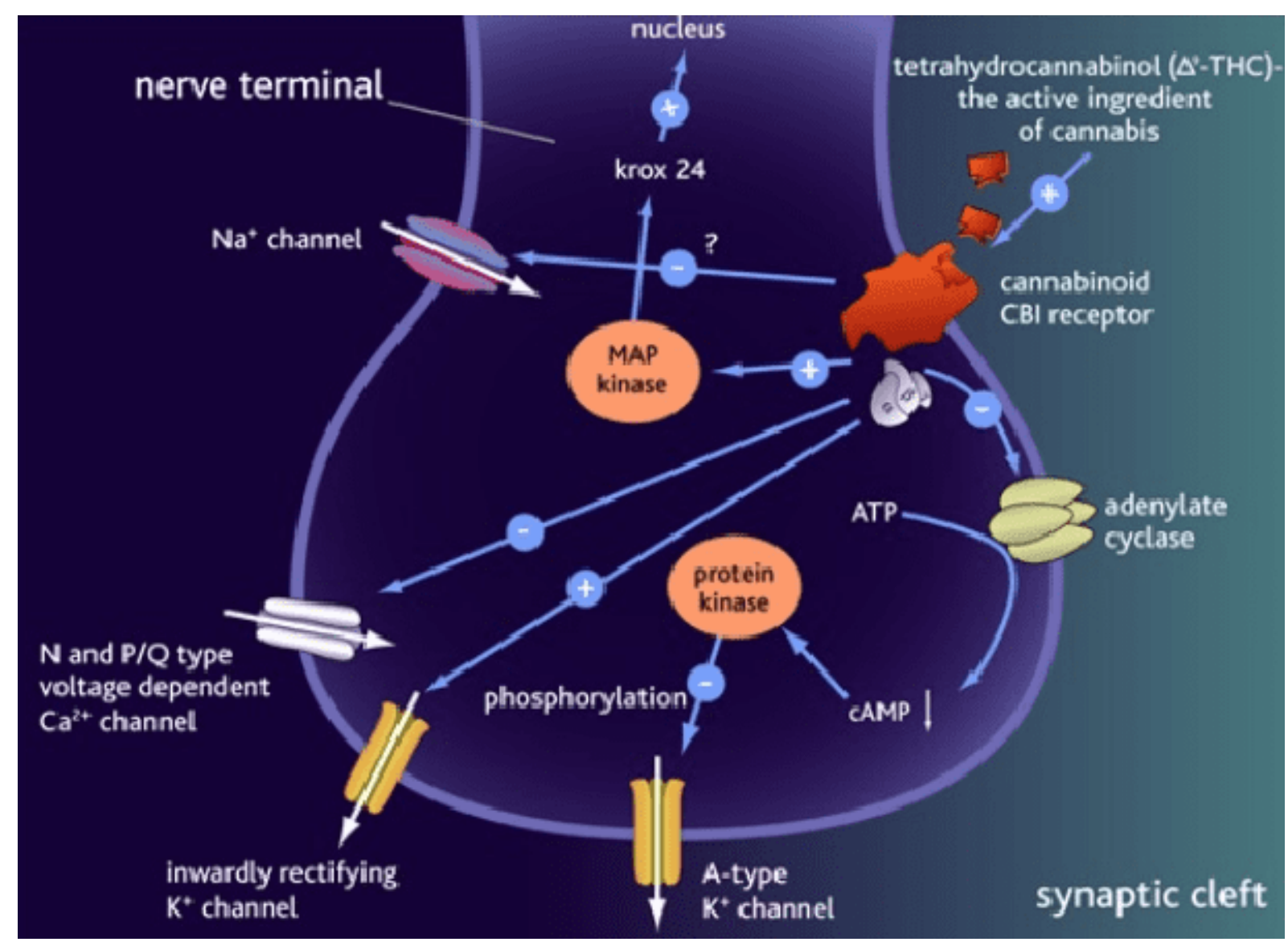

A presença desses receptores canabinóides especializados no cérebro levou os pesquisadores à descoberta de endocanabinoides, como a Anandamida e 2arachidonoyl glicerídeos (2-AG). O THC visa os receptores de uma maneira muito menos seletiva do que as moléculas endocannabinóides liberadas durante a sinalização retrógrada. Em populações de baixa densidade de receptores de canabinóides, O THC pode atuar para antagonizar os agonistas endógenos que possuem maior eficácia do receptor.O THC é uma molécula lipofílica e pode se ligar não especificamente a uma variedade de entidades no cérebro e no corpo, como o tecido adiposo.

Abreviado como CBD, o Canabidiol é um importante fitoanabinoide, que representa até $40 \%$ do extrato da planta. 
Figura 6: Fórmula estrutural do Canabidiol

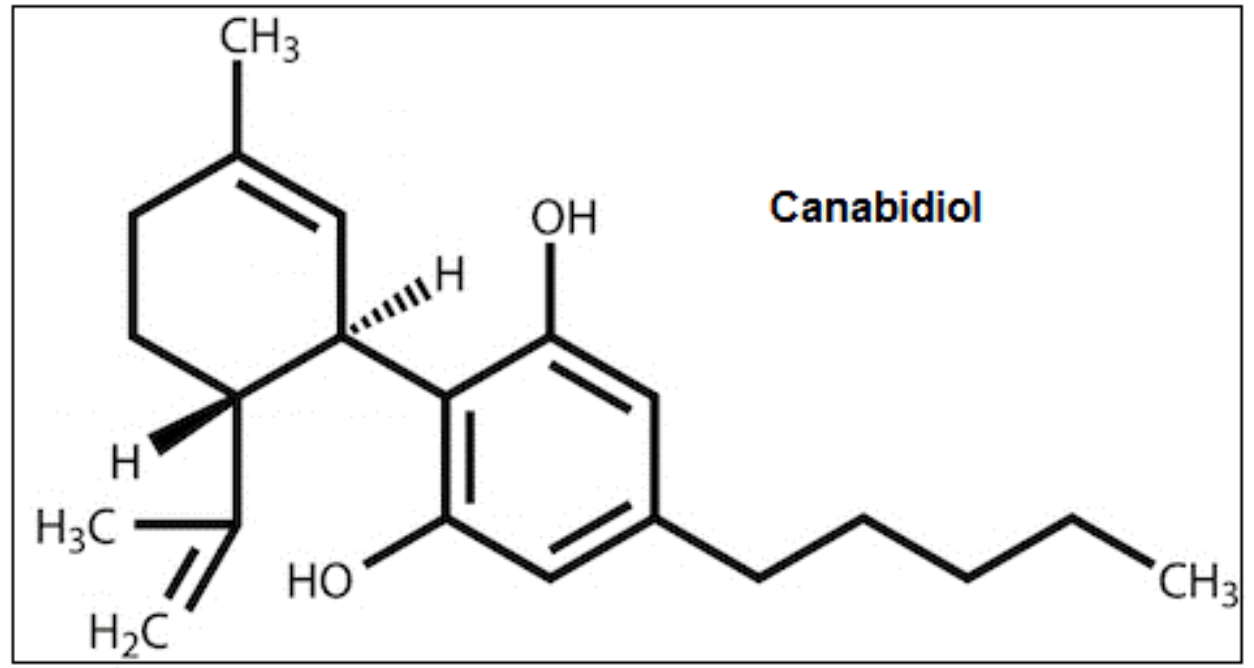

O Canabidiol tem uma afinidade muito baixa para os receptores CB1 e CB2 dos cannabinoides, mas atua como um antagonista indireto desses receptores, pode potencializar os efeitos do THC ao aumentar a densidade do receptor CB1 ou através de outro mecanismo relacionado ao receptor CB1.

Verificou-se que o Canabidiol atua como um antagonista do GPR55, um receptor acoplado a proteína $\mathrm{G}$ e receptor cannabinoide. Verificou-se também que o $\mathrm{CBD}$ pode atuar como um agonista parcial do receptor 5-HT1A, e ainda como modulador alostérico dos receptores opióides $\mu$ e $\delta$. Os efeitos farmacológicos de Canabidiol foram adicionalmente atribuídos ao agonismo de PPARY e à liberação de cálcio intracelular.

O CBD pode exercer algumas das suas ações farmacológicas através da sua inibição da amida hidrolase de ácidos graxos (Fattyacid -FAAH), que pode, por sua vez, aumentar os níveis de endocanabinoides, como a Anandamida, produzida pelo organismo.

Recentemente, o Canabidiol foi identificado como um novo agonista inverso do GPR12. 
Figura 7: Mecanismo de ação do Canabidiol ${ }^{4}$

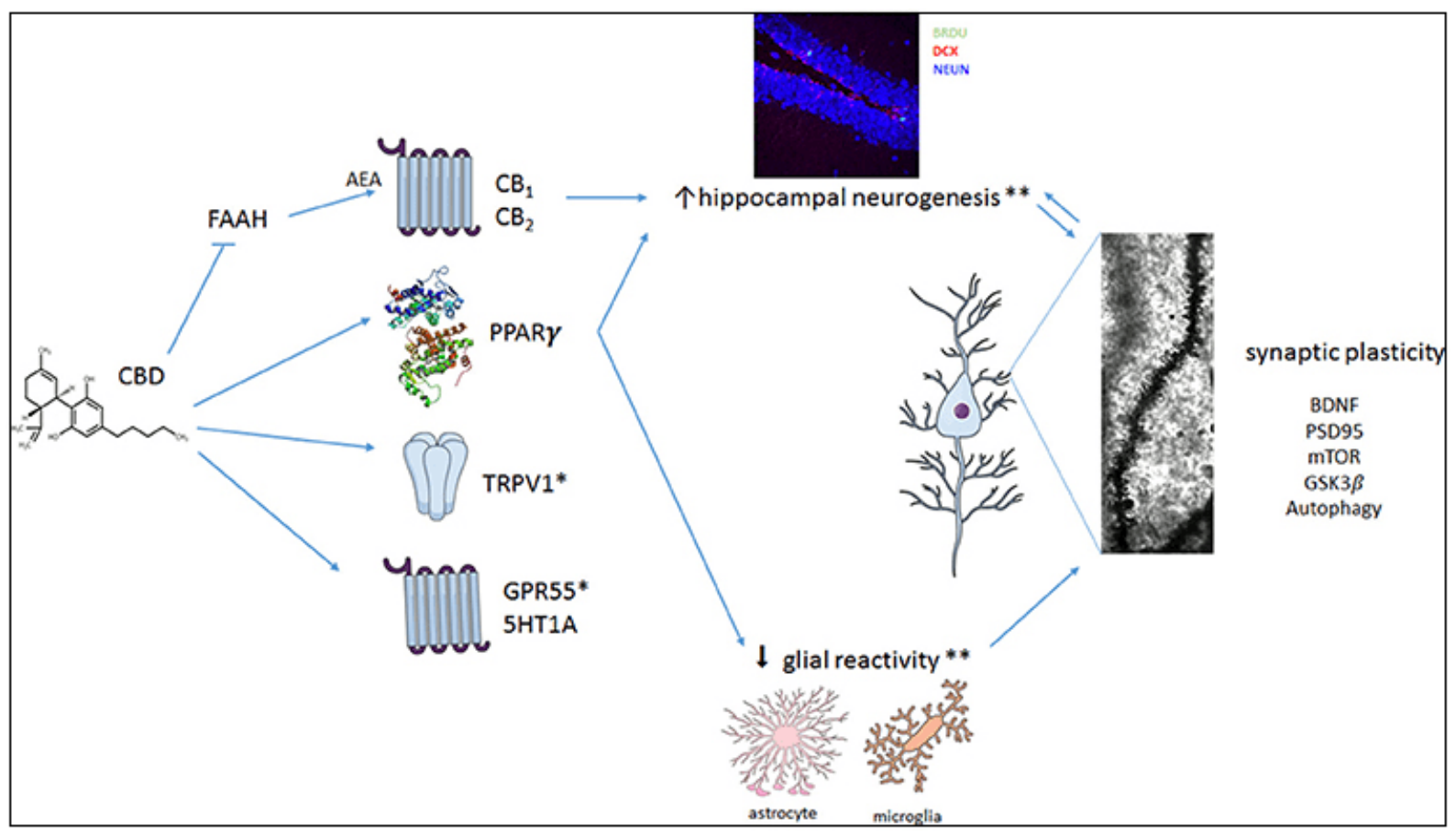

Figura 8: Diferenças entre THC e CBD ${ }^{31}$

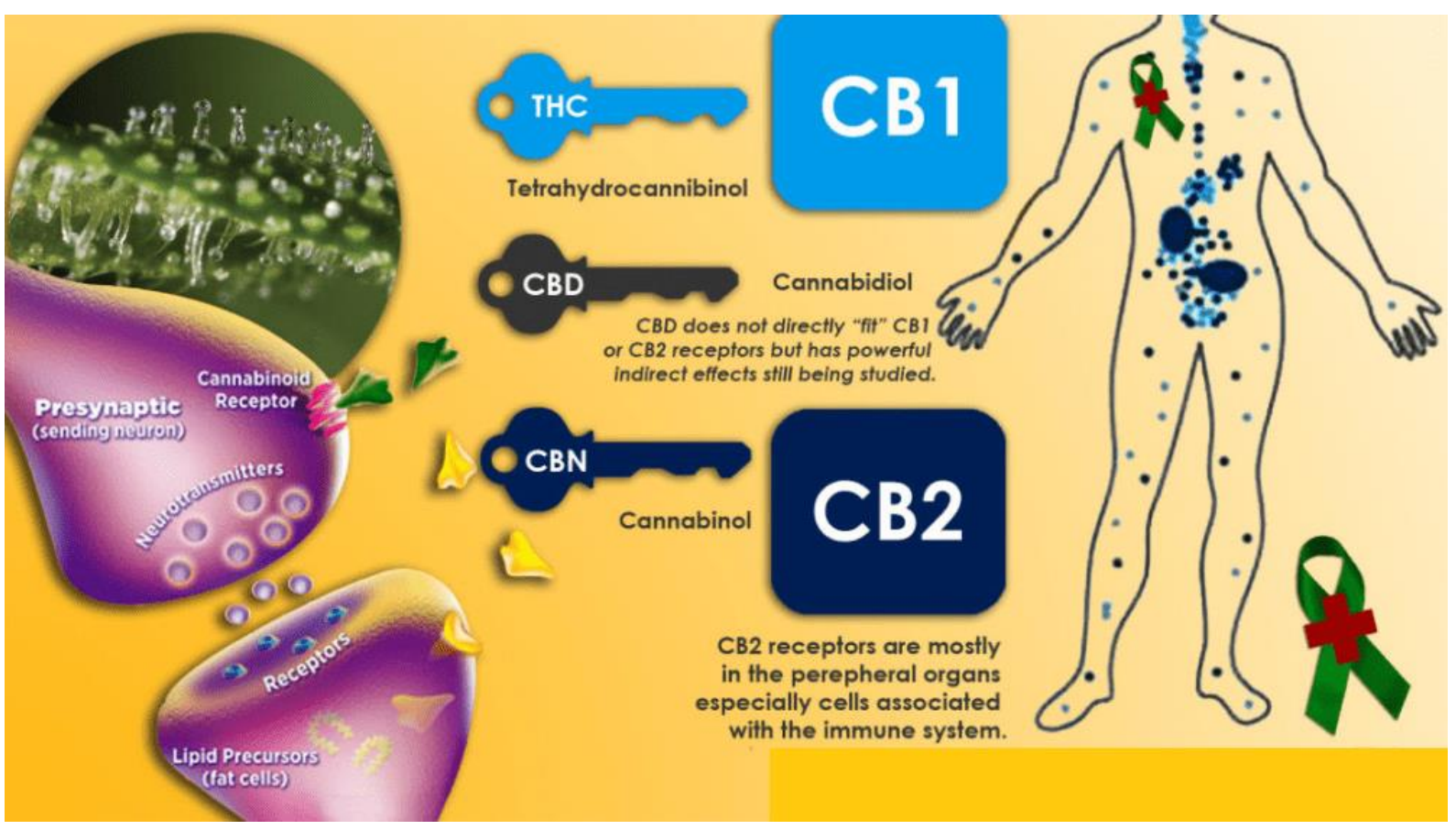




\section{PESQUISA E MEDICAMENTOS}

No Reino Unido o THC e o CBD são utilizados como ingredientes ativos do Nabiximols, medicamento de nome comercial Sativex $\AA$, um extrato específico de Cannabis que foi aprovado como droga botânica em 2010, usado como um spray bucal para pessoas com esclerose múltipla para aliviar a dor neuropática, espasticidade, bexiga hiperativa e outros sintomas.

Foi desenvolvido pela empresa britânica GW Pharmaceuticals. A droga é um produto farmacêutico padronizado em composição, formulação e dose. Os principais componentes canabinóides ativos são os canabinóides Tetrahidrocannabinol (THC) e Canabidiol (CBD). Cada spray fornece uma dose de 2,7 mg de THC e 2,5 mg de CBD.

No ano de 2017, A Agência Nacional de Vigilância Sanitária (ANVISA) aprovou o registro do medicamento específico Mevatyl, registrado em outros países com o nome comercial de Sativex® tetraidrocanabinol (THC), $27 \mathrm{mg} / \mathrm{mL}$ + canabidiol (CBD), $25 \mathrm{mg} / \mathrm{mL}$, canabinoides obtidos a partir da Cannabis sativa, na forma farmacêutica solução oral (spray) que é o primeiro medicamento registrado no Brasil à base de Cannabis Sativa.

O novo medicamento Mevatyl, é destinado a pacientes adultos não responsivos a outros medicamentos antiespásticos e que demonstram melhoria clinicamente significativa dos sintomas relacionados à espasticidade durante um período inicial de tratamento com o Mevatyl. O medicamento é destinado ao uso em adição à medicação antiespástica atual do paciente e está aprovado em outros 28 países, incluindo Canadá, Estados Unidos, Alemanha, Dinamarca, Suécia, Suíça e Israel.

Pacientes que sofrem de 30 a 80 convulsões por semana, e utilizam até quatro tipos diferentes de anticonvulsivantes, ainda assim não conseguem obter uma boa resposta ao tratamento, e muitas vezes não conseguem se manter acordados devido ao efeito dos medicamentos, tem utilizado um extrato com $20 \%$ de Canabidiol em formato de pasta. Os resultados foram fantásticos, os pacientes que sofriam de 30 a 80 convulsões por semana, passaram a ter cerca de duas por mês. Nos Estados Unidos 
o composto é considerado seguro pelo FDA (Food and Drug Administration), mas como ainda não passou por testes clínicos, as empresas que o vendem não podem alegar propriedades medicinais e o comercializam como suplemento alimentar.

Figura 9: Ação do Canabidiol contra Epilepsia ${ }^{13}$

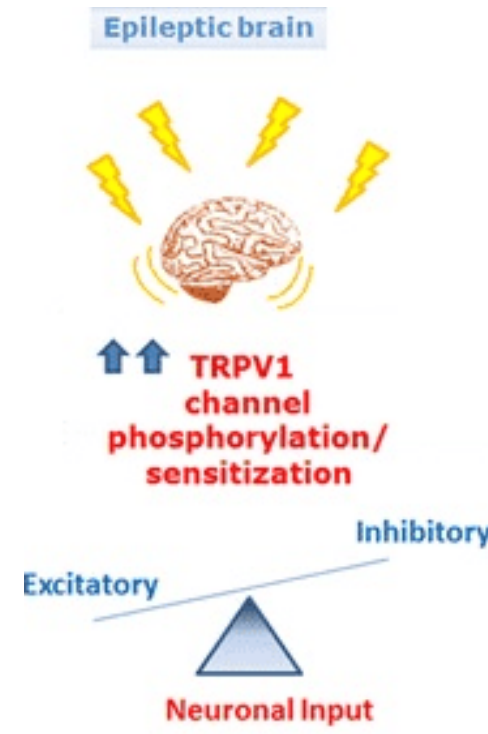

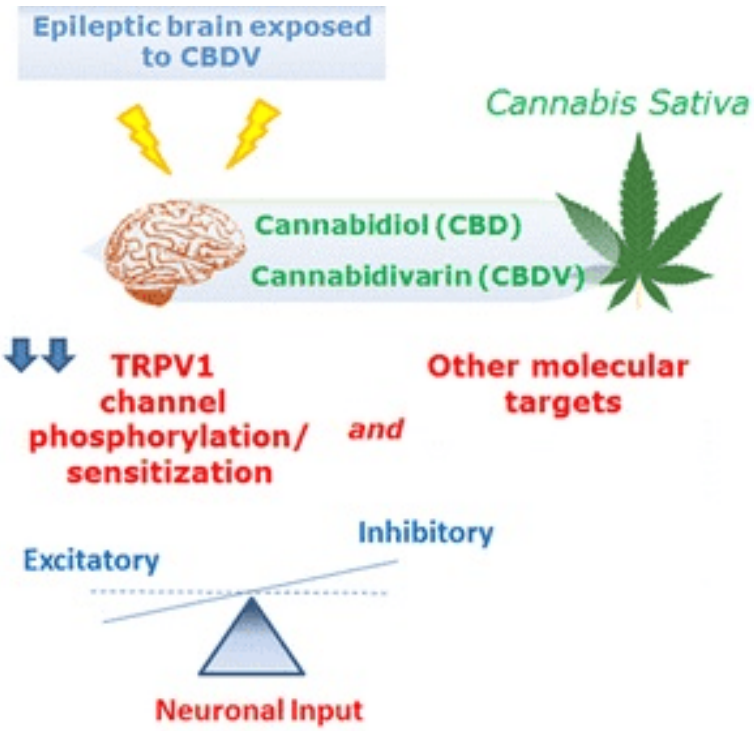

No Brasil o primeiro Centro de Pesquisas em Canabinoides será inaugurado ainda este ano na Faculdade de Medicina de Ribeirão Preto da USP, um centro para pesquisa e desenvolvimento de medicamentos contendo canabinoides. $O$ projeto, inédito no Brasil, é resultado de parceria entre a USP e a indústria farmacêutica PratiDonaduzzi. O Centro vai funcionar numa ampliação do prédio da Saúde Mental e já tem aprovado estudo clínico sobre o uso do Canabidiol, o teste será realizado em mais de 120 crianças e adolescentes com epilepsia refratária.

\section{CONSIDERAÇÕES FINAIS}

O uso terapêutico dos canabinoides derivados da Cannabis sativa tem apresentado excelentes resultados, principalmente no tratamento de convulsões e esclerose múltipla, é necessário facilitar e se intensificar as pesquisas para que novos medicamentos possam ser utilizados com segurança e eficácia, com o objetivo de aliviar o sofrimento de muitas pessoas que sofrem desses e outros males, nos quais

Disponível em: https://www.nucleodoconhecimento.com.br/saude/canabinoides 
o tratamento convencional não tem alguma melhora significativa. O Brasil devido ao clima Tropical, que favorece o cultivo da Cannabis sativa, tem a oportunidade de se tornar referência mundial neste tipo de pesquisa e desenvolvimento de novos medicamentos. O uso recreativo da Cannabis sativa deve ser combatido fortemente, além de causar dependência, pode causar alterações cerebrais e transtornos psiquiátricos graves, incluindo a morte de neurônios.

\section{REFERÊNCIAS}

1. AIZPURUA, O.; ZARANDONA, I.; ORTIZ, L.; NAVARRO, P.; ETXEBARRIA, N.; USOBIAGA, A.Cannabinoides,2016.

2. ASHTON C.H. Pharmacology and effects of cannabis: a brief review. $\mathrm{Br} J$ Psychiatry, 2001.

3. BROWN K.J., LAUN A.S., SONG Z.H, Cannabidiol, a novel inverse agonist for GPR12, 2017.

4. CAMPOS, A. C.; et al. Plastic and Neuroprotective Mechanisms Involved in the Therapeutic Effects of Cannabidiol in Psychiatric Disorders, 2017.

5. CAMPOS, A. C.; MOREIRA, F.A.; GOMES F.V.; DEL BEL E.A.; GUIMARÃES F.S. Multiple mechanisms involved in the large-spectrum therapeutic potential of cannabidiol in psychiatric disorders, 2012.

6. Clinical Effects, Academic Press, 1973.

7. ELPHICK M.R.; EGERTOVÁ M. The neurobiology and evolution of cannabinoid signalling. Philosophical Transactions of the Royal Society B: Biological Sciences, 2001.

8. HART, G. The Routledge Dictionary Of Egyptian Gods And Goddesses, 2005.

9. HAYAKAWA, K.; et al. Cannabidiol potentiates pharmacological effects of Delta (9)-tetrahydrocannabinol via CB (1) receptor-dependent mechanism, 2008.

10. HILL, B. Cannabis: A Journey Through the Ages, 2015.

11. HONÓRIO, K. M.; ARROIO, A.; DA SILVA, A. B. F. Aspectos Terapêuticos de compostos da planta. Cannabis sativa, 2006.

12. HUESTIS, M. A. Humancannabinoidpharmacokinetics, 2007. 
13. IANNOTTI, FABIO ARTURO; et AL. Nonpsychotropic Plant Cannabinoids, Cannabidivarin (CBDV) and Cannabidiol (CBD), Activate and Desensitize Transient Receptor Potential Vanilloid 1 (TRPV1) Channels in Vitro: Potential for the Treatment of Neuronal Hyperexcitability, 2014

14. Jornal da USP, fevereiro de 2017.

15. KATHMANN M, FLAU $K$, REDMER A, TRÄNKLE C., SCHLICKER E. Cannabidiol is an allosteric modulator at mu- and delta-opioid receptors, 2006. 16. LOPES, RENATO MALCHER; RIBEIRO, SIDARTA. Cérebro e Saúde, Vieira \& Lent, 2007

17. MECHOULAM R, PETERS M., RODRIGUEZ E., HANUS L.O. Cannabidiol recent advances, 2007.

18. MECHOULAM, R. Marijuana: Chemistry, Pharmacology, Metabolism and Clinical Effects, Academic Press, 1973.

19. MECHOULAM, R.; BEN-SHABAT, S. Nat. Prod.Rep, 1999.

20. Multiple Sclerosis Trust.Sativex (nabiximols) - factsheet,2014

21. NAHAS, G. G. Marihuana in science and medicine, Raven Press, 1984.

22. PERTWEE, R.G. The diverse CB1 and CB2 receptor pharmacology of three plant cannabinoids: delta9-tetrahydrocannabinol, cannabidiol and delta9tetrahydrocannabivarin, 2008.

23. RYBERG E.; et al. The orphan receptor GPR55 is a novel cannabinoid receptor, 2007

24. SativexOromucosal Spray - Summary of Product Characteristics". UK Electronic Medicines Compendium, 2015.

25. TAKAHASHI, R. N.; ZUARDI, A. W.; KARNIOL, I.G. Chemical composition of Brazilian marihuana samples and the importance of several constituents to the pharmacological activity of the plant, 1977.

26. VARELA, D. Cannabis: Esperança contra convulsões, 2014.

27. WATANABE, K.; YAMAORI S.; FUNAHASHI T.; KIMURA T.; YAMAMOTO I. Cytochrome P450 enzymes involved in the metabolism of tetrahydrocannabinols and cannabinol by human hepatic microsomes, 2007.

28. http://biocannamed.eu/content/9-cbd-cannabinoids Acesso 02/2018 29. https://maryjuana.com.br/2017/01/seshat-deusa-maconha/ - Acesso 02/2018 
30. http://healthmarijuanacanada.blogspot.com/2015/02/emerging-clinicalapplications-for.html Acesso 02/2018

31.https://cannabismo.ca/science-behind-cannabis/ Acesso 02/2018

Enviado: Março, 2018.

Aprovado: Julho, 2019. 